\title{
MEMÓRIAS E SIGNIFICADOS DE DANÇAR POR MUITOS ANOS: O QUE NOS DIZEM IDOSOS QUE DANÇARAM AO LONGO DA VIDA
}

\author{
MEMORIES AND MEANINGS OF DANCING FOR MANY YEARS: WHAT ELDERS \\ WHO HAVE DANCED THROUGHOUT LIFE TELL US
}

\author{
MEMORIAS Y SIGNIFICADOS DE BAILAR POR MUCHOS AÑOS: LO QUE NOS \\ DICEN ANCIANOS QUE BAILARON A LO LARGO DE LA VIDA
}

\author{
Rute Estanislava Tolocka*, Lia Carla Gordon Leme*, \\ Valquiria Maria Tolocka Gomes da Silva**
}

Palavras chave

Dança.

Idoso.

Exercício.

Memória.
Resumo: Uma das atividades mais procuradas por idosos é a dança, mas o significado de dançar nessa idade ainda precisa ser desvelado. $O$ objetivo deste estudo foi identificar memórias e significados que a prática da dança ao longo da vida trouxe a seus praticantes. Entrevistamos idosos que dançam em média há 57 anos. Para construir as memórias utilizamos a técnica da História Oral e para extrair significados de dançar utilizamos os pressupostos da Teoria Bioecológica do Desenvolvimento Humano. Os temas que emergiram das entrevistas foram: dança como hábito de vida; caminhos percorridos para aprender a dançar; motivos relacionados à prática da dança e significados de dançar. Eles começaram a dançar pela influência de familiares e amigos, continuam a dançar e preferem evocar apenas boas lembranças. Dançando modificaram e foram modificados pelos diferentes ambientes. Dançar constituiu-se em possibilidade de resiliência, que alimenta a própria possibilidade de dançar e acrescenta vontade de viver.
Keywords:

Dancing.

The elderly.

Exercise.

Memory.

Palabras clave:

Baile.

Anciano.

Ejercicio.

Memoria.
Abstract: One of the activities most often sought by the elderly is dancing. However, the meaning of dancing at that age remains to be examined. This study aimed at identifying memories and meanings brought by dancing to its practitioners throughout their lives. We interviewed elderly people who have danced for 57 years on average. For eliciting those memories, we used the Oral History technique; for extracting the meanings of dancing we used assumptions from Bioecological Theory of Human Development. The themes that emerged from the interviews were: Dancing as a life habit; Pathways travelled for learning how to dance; Reasons to practice dance; and the Meanings of dancing. They started to dance influenced by family and friends; now they keep dancing and they prefer evoking only good memories. By dancing they changed and were changed by the different environments. Dancing is a possibility for resilience, which drives the very possibility of dancing and adds will to live.

Resumen: Una de las actividades más buscadas por ancianos es la danza, pero el significado de bailar a esa edad todavía necesita ser desvelado. El objetivo de este estudio fue identificar memorias y significados que la práctica del baile a lo largo de la vida trajo a sus practicantes. Entrevistamos ancianos que bailan, en media, hace 57 años. Para construir las memorias utilizamos la técnica de la Historia Oral, y para extraer significados de bailar utilizamos los argumentos de la Teoría Bioecológica del Desarrollo Humano. Los temas que se emergieron en las entrevistas fueron: baile como hábito de vida; caminos recorridos para aprender a bailar; motivos relacionados con la práctica del baile y significados de bailar. Ellos empezaron a bailar por la influencia de familiares y amigos, siguen bailando y prefieren evocar solo buenos recuerdos. Bailando modificaron y fueron modificados por los diferentes ambientes. El baile se costituyó en una posibilidad de resiliencia, que alimenta la propia posibilidad de bailar y aumenta la voluntad de vivir.
* Universidade Metodista de São Paulo (UNIMEP). Piracicaba, SP, Brasil. E-mail: tkiva05@yahoo.com.br, licgleme@gmail.com

** Secretaria Estadual de Educacão de São Paulo. São Paulo, SP, Brasil. E-mail: valgomes@ hotmail.com

Recebido em: 11/07/2017 Aprovado em: 27/11/2018

DOI: https://doi.org/10.22456/1982-8918.74922 (c) (1) (8) Licence Creative Commom 


\section{INTRODUÇÃO}

Vários programas para a terceira idade têm surgido e incentivado a prática de atividades físicas sob a premissa de que esta prática é um meio eficaz de promoção da saúde e prevenção de doenças (EYIGOR et al., 2009; HUI; CHUI; WOO, 2009).

A dança é uma das atividades mais procuradas pelos idosos e a maioria dos estudos sobre dançar na terceira idade concentra-se em apontar benefícios dessa prática em aspectos específicos. Dentre eles, podemos citar os que apontam para aspectos físicos, tais como melhoras na estabilidade postural (ZHANG et al., 2008), no equilibrio (EYIGOR et al., 2009; JEON; CHOE; CHAE, 2000; LIMA; VIEIRA, 2007; MAVROVOUNIOTIS; ARGIRIADOU; PAPAIOANNOU, 2008; MCKINLEY et al., 2008; SHIGEMATSU, 2002; SOFIANIDIS et al., 2009; VERGHESE, 2006; WALLMANN et al., 2009), na marcha (JEON; CHOE; CHAE, 2000; MCKINLEY et al., 2008; SHIGEMATSU et al., 2002; VERGHESE, 2006; WU et al., 2010), na coordenação motora, força e flexibilidade (CASSIANO et al., 2009; CONNOR, 2000; LIMA; VIEIRA, 2007; VALLE et. al., 2017), na capacidade de desenvolver força explosiva (PEREIRA; SCHETTINO; MACHADO, 2010), auxílio para prevenção de quedas (JEON et al., 2005; MCKINLEY et al., 2008; SOFIANIDIS et al., 2009) e melhora cardiovascular (COUDERT; VAN PRAAGH, 2000).

Encontramos também benefícios para a interação social (ALLEN, 2003; CASSIANO et al., 2009; COOPER; THOMAS, 2002; FLEURY; GONTIJO, 2006; HUI et al., 2009; LIMA; VIEIRA, 2007; SILVA; MAZO, 2007; WALLMANN et al., 2009), qualidade de vida (CARTA et al., 2008, EYIGOR et al., 2009; MAVROVOUNIOTIS et al., 2008), manutenção da memória (CASSIANO et al., 2009; CONNOR, 2000; FLEURY; GONTIJO, 2006; WALLMANN et al., 2009) e melhoria nas funções cognitivas e percepto-motoras (WU et al., 2010).

Entretanto, para além desses benefícios, a experiência de dançar para os idosos é mais do que uma possibilidade de praticar atividades físicas, constitui-se também em uma experiência positiva, que pode ocorrer de forma espontânea e/ou coreografada e em diversos espaços (SILVA; MAZO, 2007) e trazer boas memórias, conexões culturais e oportunidades de socialização (LEAL; HASS, 2006; LIMA; VIEIRA, 2007).

Em muitos países, dançar é parte da vida diária, da infância à terceira idade (CONNOR, 2000), no entanto, a maioria dos estudos sobre terceira idade são feitos com pessoas que já estão nessa fase da vida e não se distinguem resultados em relação à experiência anterior e à observada durante os estudos, o que pode mascarar os achados.

Experiências vividas ao longo da vida influenciam no estado atual, sendo necessário recuar no passado para apreciar a importância e a dimensão a longo prazo dos fenômenos. Como afirmou Thompson (1992), o passado lembrado tem valor histórico e proporciona informação significativa e, por vezes, única sobre o passado, além de transmitir a consciência individual e coletiva que é parte integrante desse mesmo passado.

Burke (1992) observou que a história da vida cotidiana já foi tratada como trivial, mas é com ela que tudo deve estar relacionado. Depoimentos orais preenchem lacunas deixadas por outras fontes, constituindo-se em novas fontes históricas que podem ser analisadas para observar como o desenvolvimento humano ocorre ao longo do tempo.

Características pessoais interagem com contextos ambientais imediatos e/ou remotos e essas relações transformam tanto as pessoas como os contextos ambientais 
(BRONFENBRENNER, 2005), de maneira que, para se entender melhor os resultados sobre atividade física e pessoas da terceira idade, se faz necessária também a verificação de como esta prática foi construída e o que significou.

Desta forma, este estudo teve como objetivo identificar memórias e significados que a prática da dança ao longo da vida trouxe a seus praticantes.

\section{DELINEAMENTO METODOLÓGICO}

Nossa busca por idosos que praticavam a dança por um longo período de suas vidas se deu a partir de convite feito a todos os 1287 idosos que compunham a Associação dos Grupos de Terceira Idade (AGTIP) de uma cidade no estado de São Paulo, bem como todos os moradores ou frequentadores de uma residência para idosos, na mesma cidade, que promovia bailes semanalmente.

Nestes locais, solicitamos que os que assim o desejassem preenchessem uma ficha sobre prática de atividades físicas (tipo e tempo de prática) e os que se reportaram à dança como prática regular, por muitos anos consecutivos, foram selecionados para este estudo, desde que assinassem o Termo de Consentimento Livre e esclarecido para a sua realização. Foram encontrados 25 idosos que tinham entre 39 e 75 anos de prática de dança ininterrupta e concordaram em participar do estudo, sendo 17 mulheres e oito homens.

Convidamos estes idosos a participar de uma entrevista semiestruturada, com perguntas abertas, as quais foram elaboradas de acordo com as instruções de Ludke e André (1986) e previamente testadas e posteriormente adequadas, em um estudo piloto, com cinco pessoas, sendo quatro idosos e um profissional que trabalhava com dança em grupos de idosos.

Tais entrevistas foram compostas por questões que versavam sobre: idade, sexo, tempo e locais de prática da dança, como se deu a aprendizagem da dança, qual o significado de dançar para a pessoa, para a comunidade onde viviam e para a comunidade onde se inseriam à época da entrevista e sentimentos que tinham ao dançar ou não.

As entrevistas foram gravadas e analisadas de acordo com a técnica de história de vida, proposta por Thompson (1992) com as seguintes etapas: transcrição integral da fala dos informantes, conferência do material oral com o impresso, transcrição para a linguagem acadêmica e levantamento de categorias de interpretação e análise do material, agrupando-o em torno de temas comuns. Essa técnica permite uma reconstrução de uma história vivida que traz consigo temas a serem analisados; os que emergiram destas entrevistas foram: Dança como hábito de vida; Caminhos percorridos para aprender a dançar; Motivos relacionados à prática da dança e Significados de dançar.

Para desvelar o significado atribuído à dança, considerando-se não apenas as questões específicas sobre este item, mas também o conjunto de dados analisados, tivemos como base os pressupostos da teoria bioecológica do desenvolvimento humano, proposta por Bronfenbrenner (1992, 2005).

\section{A DANÇA COMO HÁBITO DE VIDA}

Quase todos os idosos dançavam há a mais de meio século (o tempo médio com atividades em dança foi de $=56,76$ anos; com desvio padrão $=1,8$ anos) sendo que 0 idoso 
que dançava há menos tempo o fazia há pelo menos 39 anos e o que dançava há mais tempo o fazia há 75 anos.

A maioria começou a dançar na adolescência, por volta dos 15 anos de idade (a menor idade de iniciação à dança foi entre cinco e seis anos e a maior 18 anos). Eles começaram a dançar ainda na infância ou adolescência, ou porque os pais e amigos já dançavam, ou porque era o que se tinha para fazer como lazer e diversão. Por exemplo, a idosa com entrevista $n^{0 .} 6$, E6, explicou: "[...] porque a gente ia com a mãe da gente, né? Então, eu comecei, eu tinha uns 12 anos por aí". Outros exemplos foram: "Ah, eu tinha uns cinco ou seis anos. Aprendi a dançar no sítio, junto com os meus pais" (E25). "Eu tinha nove anos. Aprendi com a minha mãe e 0 meu padrasto, que era sanfoneiro. Eu sou filha única, tinha que nos ir no baile com eles" (E1). "Comecei a dançar com dez ou 12 anos... Ah, a gente dançava na fazenda. Meu pai ia montar máquina de café e tinha bailinho. A gente dançava, né?" (E9).

Todos dançavam em algum tipo de baile, que ocorria, na maioria das vezes, em fazendas ou sítios "[...] eu morava na fazenda, né [...], lá havia um conjunto que tocava e nós dançávamos [...]" (E10). "[...] Era aqueles bailinhos de chão de terra [...]" (E13).

O meu pai participava assim de festas, sabe? O meu tio tocava violão, então a gente ia com meu pai, com meu tio... a gente ia em festa de casamento, festa de igreja, festa de São João, Santo Antônio, sabe? Estas festas comemorativas e São Benedito, então, eles iam tocar violão e a turma dançava, tocava sanfona, tinha sanfona, tudo... e a gente dançava (E8).

$\mathrm{Na}$ fase adulta, a maioria dos idosos nunca parou de dançar, mesmo com o aumento das responsabilidades, como diz E13, "A gente nunca parou, sempre continuou mesmo [...] na fase que a gente trabalhava, sempre ia a bailes no clube da empresa nos sábados [...]" ou "[...] até quando eu viajava, quando eu era chefe de montagem, tinha festa baile eu ia [...] (E9).

O local dos bailes passou, então, dos encontros em fazendas para clubes, pois muitos idosos que moravam na infância ou adolescência na zona rural se mudaram para a cidade na fase adulta:. "[...] quando eu me mudei para cidade a gente frequentava os clubes" (E-25).

Hoje em dia, a prática da dança se mantém por no mínimo duas vezes por semana, para dez desses idosos; os outros 14 o fazem uma vez por semana e um deles, uma vez por mês. Eles dançam em diferentes locais da cidade, onde essas atividades são oferecidas: sindicatos, clubes, varejões, salão de igreja, centros comunitários, lar para idosos ou mesmo em casa, em festas da família.

Vários idosos participam de bailes em mais de um local: "[...] danço na AGTIP, no clube do saudosista [...] não dá para gente ir em tudo, então a gente tem que escolher um lugar para ir" (E8).

"Hoje [eu danço] no clube do saudosista, aqui [uma residência para idosos], no AGTIP e em todos os salões que tem na cidade" (E20).

Podemos assim afirmar que dançar tem sido um persistente hábito na vida desses idosos por mais de meio século, mesmo em um contexto em que o sedentarismo tem sido crescentemente reportado com índices cada vez maiores (INSTITUTO BRASILEIRO DE GEOGRAFIA E ESTATÍSTICA, 2017; KNUT, et al., 2011) e mesmo com as dificuldades próprias das limitações advindas do processo de envelhecimento. 
Isto mostra que a dança proporcionou aderência à atividade física, ao longo do tempo, o que revela que se constituiu em uma atividade molar, ou seja, atividade que possui significado e relevância, que leva ao engajamento e persistência e que por isso se torna frequente no cotidiano das pessoas.

Esses idosos começaram a dançar por causa da família, no seu ambiente imediato (microssistema) ou a convite de amigos (outro ambiente imediato) e saíram para dançar, conhecendo assim mais um ambiente. Mantendo a frequência entre a casa, o local de dançar e outros locais onde encontravam amigos, tinham a dança como elo nos três ambientes (que formava um mesossistema) e assim prosseguiram conhecendo diferentes ambientes e pessoas, influenciados pelas manifestações culturais, em diferentes tipos de festa (casamento, festas religiosas ou encontros em salões de dança). Dançando estas pessoas influenciaram 0 surgimento e o funcionamento de processos proximais futuros, que são mecanismos primários do desenvolvimento humano (BRONFENBRENNER, 2005).

\section{CAMINHOS PERCORRIDO PARA APRENDER A DANÇAR}

Mas, como foi que eles se iniciaram nesta atividade e como o processo se deu para que dançar passasse a ser um hábito de vida?

Não foi na escola que esses idosos aprenderam a dançar; todos eles afirmaram que nunca tiveram aula de dança na escola. Eles aprenderam a dançar de maneira informal, frequentando bailes desde a infância ou adolescência. A maioria deles aprendeu a dançar com algum familiar ou com amigos.

Para aprender a dançar eles recebiam dicas, por exemplo, de como movimentar o corpo "[...] Então era um pra lá dois pra cá, e na valsa tem erguer o pé, meu pai falava para mim [... "Ele [pai] falava: - Vai põe o pé para trás, põe o pé para frente assim [...]" (E4).

Eles também procuravam observar as pessoas dançando. Olhavam para os pés, ou sentiam o ritmo da música nos pés ou ainda observavam qual pessoa dançava melhor.

\footnotetext{
A gente tem que observar se a pessoa dança bem, então vem, tira você, daí você vai dançar. Se a pessoa não dança, ela lhe arrasta, então você não vai... Daí você aprende com a pessoa que vem tirar você. Você não sabe muito, então você aprende com aquela pessoa, e eu gosto muito de ensinar. Eu olhava se dançava direitinho, se fazia os passos direitinho... olhava nós pés (E3).
}

Olhava nas pessoas, olhava no corpo, o jeito que ela fazia movimento no pé... movimento no pé e no corpo (E5).

A gente olhava mais para os pés das pessoas, como eles movimentavam. É, porque é o pé que é mais importante $[\ldots](E 8)$.

Ah, eu olhava nos pés e no corpo, como a pessoa é, o comportamento da pessoa para você aprender. Então, eu ficava prestando bem atenção no que a pessoa fazia para depois eu fazer (E11).

Ao reparar no outro a dançar (díadas de observação), ao receber dicas sobre movimentos a serem executados e/ou executar o movimento em conjunto com o outro (díadas de participação conjunta), eles foram estabelecendo relações sociais que foram evoluindo, vínculos que foram se fortalecendo e mesmo quando o outro não estava fisicamente presente, sua lembrança o trazia para o ambiente (díada primária). Isto, ocorrendo ao longo do tempo, 
tornou a atividade mais significativa, pois o "professor" não era apenas um professor, mas uma pessoa com quem se tinha laços de amizade profundos, o que pode ter atuado como mola propulsora para que dançar se tornasse um hábito de vida permanente (BRONFENBRENNER, 1996).

Apenas um dos entrevistados aprendeu a dançar de maneira formal com um professor de dança, mas mesmo assim, o fez em bailes em um clube e não em uma escola. Ele conta que o professor de dança "era bom", ensinava os passos da dança e dava dicas sobre movimentar o corpo. "Falava para mexer o corpo [...]" (E5).

Como a experiência de dançar se deu, na maioria das vezes, dentro de bailes, a dança de salão foi, e continua a ser, a dança vivenciada por eles. Entre as diferentes possibilidades da dança de salão, foram citadas a valsa e o tango, bem como o samba, o vanerão, o forró e a rancheira.

Embora os estilos de dança por eles praticados continuem os mesmos, há reconhecimento de diferenças, principalmente atreladas ao ritmo: "[...] passos mais lentos" (E3) ou "[...] o jeito de dançar é mais agitado" (E22) ou ainda "[...] agora essas danças que passam na televisão eu não sei dançar nada e o tango eu também não sei" (referindo-se a um programa de televisão que é uma competição de dança) (E13). Dançando esses idosos prosseguiram observando, aprendendo e ensinando anos afora.

Acolher o outro para dançar e ou ensinar-lhes passos de dança (disposições comportamentais ativas) permitiu-lhes o desenvolvimento de recursos pessoais, que auxiliavam não apenas na realização da tarefa, mas no fortalecimento das relações pessoais e no desenvolvimento de papéis sociais, de acordo com as demandas ambientas que surgiam. As disposições pessoais ativas influenciam os processos proximais de forma positiva, mantendo-os em movimento (BRONFENBRENNER; MORIS, 2006), ou seja, a interação desses elementos fortaleceu a prática da dança.

\section{MOTIVOS RELACIONADOS À PRÁTICA DA DANÇA}

Ao analisarmos os depoimentos sobre os motivos que levaram ao início da prática da dança, verificamos a existência de um elemento comum: uma outra pessoa, que lhe era cara: um familiar ou amigo. A memória traz à tona que o prazer pela dança já estava presente nos que lhes ensinaram a dançar e se associa com bons momentos por eles vivenciados, por exemplo:

[...] Eles [pais] eram apaixonados por dançar, tinha um almoço, depois o almoço se tornava em dança. (E11). [...] Meu pai, e minha mãe e a família inteira adoravam dançar (E15).

Ah, eles achavam que deviam dançar, né, era um divertimento, era a única coisa que tinha, porque a gente foi criada no sítio, quando tinham estas coisas tínhamos que aproveitar (E17).

[...] No sítio era uma união entre as pessoas e era como uma família, todo mundo reunido, dançando (E25).

Vemos, assim, que benefícios psicossociais da prática da dança estiveram presentes nas diferentes fases da vida dessas pessoas. 
Como eles vivenciaram a dança de salão, que eram as danças populares da época em que se iniciaram na dança, e como estas eram dançadas sempre com um parceiro, que na maioria da vezes eram pessoas do sexo oposto, conhecidas no próprio baile, a dança oportunizou também a vivência de romances, como explica E16: "[...] naquele tempo a gente ia ao baile e sempre aparecia uma namoradinha... É porque lá o baile era assim, as damas ficavam de um lado e os cavalheiros de outro, então a gente convidava a dama [ para dançar] $[\ldots] "$.

Destas relações sociais nasceram uniões duradouras, como, por exemplo, matrimônio: "[...] depois que conheci a minha esposa [...] só dançava com ela" (E12) ou "A maior parte do tempo eu dançava com a minha esposa [...]" (E24).

Verificamos também que continuar a dançar mantém a possibilidade de interações sociais: " [no baile] faz-se novas amizades..." (E4) ou "[no baile] a gente observa que são todos colegas e todos estão alegres... vão [no baile] porque é um lugar que a gente se sente bem" (E8).

Dançar auxilia esses idosos a aliviar as tensões do dia a dia e a se desvencilhar de sentimentos negativos, tais como a tristeza, e se concentrar só na dança. Isso pode ser observado nos seguintes relatos:

[...] eu acho que a gente tem que dançar sentindo a música, prestando atenção na música, né? Então tem aquele prazer de dançar ( $\mathrm{E6}$ ).

[...] você se solta, esquece de tudo, pensa no que você está fazendo, que é a dança, né? (E7).

Ah, a dança pra mim parece uma terapia. Eu chego no baile e parece que sou outra pessoa $[\ldots]$ (E1).

Dançar me traz alívio e descanso para o corpo (E5).

Os depoimentos sobre sentimentos produzidos quando não dá para ir dançar na maioria das vezes são entremeados de tristeza, raiva ou solidão:

Ah, eu fico chateada quando não dá pra eu ir [ao baile] [...] (E18).

Vamos ao clube dançar, lá a gente esquece [dos problemas]... sinto falta de dançar, falta de sair de casa, de participar, de ouvir música, de estar no meio de pessoas (E4).

Eu sou sozinha onde eu moro... ninguém sai comigo se não vou dançar, ninguém fica comigo (E22).

Ainda há casos de idosos que sentem diferenças fisicamente quando não podem dançar: "Eu sinto o corpo bem atrofiado" (E17). "Ah a gente fica meio fora de forma, engorda um pouco, fica com a respiração mais ofegante" (E7).

Verificamos novamente que as inter-relações pessoais foram importantes para a prática da dança, o outro não era apenas o professor, mas era também um importante motivo para dançar. Nas relações estabelecidas tinha-se a chance de vivenciar disposições ativas ou disruptivas (por exemplo, quando alguém manifestava que não queria dançar com determinada pessoa, ou realizar alguma outra tarefa proposta no ambiente onde a dança ocorria). Podiase também desenvolver recursos pessoais (características pessoais, ativos e passivos biopsicológicos, motores ou sexuais) e levar e trazer informações de outros ambientes, que não os da dança, enriquecendo a ambos (BRONFENBRENNER, 2005). 
Isto trouxe a ideia de que dançar diminui a tristeza, traz alegria, companhia e permite "ficar em forma", ou seja, os idosos afirmam diferentes aspectos do comportamento que são modificados por esta prática, reforçando a ideia de que as características pessoais se desenvolvem com a dança e que isso alimenta a vontade de dançar.

Assim, dançar ao longo da vida levou essas pessoas a querer e a sentir necessidade de continuar dançando, dançar lhes dava alegria se o fizessem e tristeza se isso não ocorresse, sentimentos estes que se mantêm até hoje e levam à manutenção desta prática.

\section{SIGNIFICADOS DE DANÇAR}

Quando indagados sobre o significado que a dança tem para eles, dez idosos afirmaram que se trata de uma atividade essencial para a vida. Encontramos expressões como: "tudo"; "minha vida", "não consigo viver sem ela", "tenho paixão por ela", dentre outras afirmações semelhantes. Cinco idosos se referiram à dança como uma oportunidade para fruir o lazer (se distrair, se divertir, viajar), outros quatro como uma possibilidade de realizar atividade física. Foram reportados também sentimentos de alegria, felicidade e bem-estar.

O significado desta atividade para alguns deles é tão intenso, que os impulsiona a querer dançar ainda mais:

[...] não consigo viver sem ela, gosto muito de dançar. A única coisa que eu não consigo viver sem é a dança (E1).

[...] depois que comecei não parei ainda [...] eu gosto demais de dançar, não tem explicação o quanto que eu gosto de dançar [...]. Quero morrer em um salão dançando, de tanto que eu gosto. Se eu morrer, morro feliz (E11).

[...] eu danço porque eu gosto mesmo de dançar (E6).

[...] eu espero dançar muito, muito mais (E20).

[...] danço três vezes por semana, mas por mim eu dançava todo dia (E2).

Os achados aqui narrados apontam para a ideia de que dançar ao longo da vida foi fortalecendo a vontade de dançar, a ponto de se tornar uma atividade essencial e desejável, que proporciona possibilidades de convívio social e bem-estar psicológico.

No estudo realizado por Leal e Hass (2006) sobre o significado da dança para os idosos também foi encontrado que a prática da dança se constitui em uma atividade prazerosa que proporciona bem-estar social, psicológico e físico e Cassiano et al. (2009), bem como Oliveira e Tolocka (2009), evidenciaram o desenvolvimento de relações interpessoais através da dança em grupos com idosos.

Além disso, Cooper e Thomas (2002) destacaram que a dança é um elemento que pode auxiliar na transição de uma faixa etária para outra, em âmbito psicossocial, ou seja, concede benefícios significativos para aqueles que estão entrando na terceira idade. Eles também falaram sobre a convivência social que a dança pode proporcionar para esta população. Lima e Vieira (2007) consideram que a dança de salão institui uma "cultura de inclusão" para a aceitação entre os idosos e assim também pode ajudar a qualidade de vida destes.

O estudo de Silva et al. (2016), realizado com cuidadoras de pessoas com deficiências, também encontrou que a dança modificou significativamente a vidas dessas pessoas trazendo bem-estar e vontade de continuar a dançar. 
Desta maneira vemos que dançar pode auxiliar a enfrentar mudanças e assim amenizar perdas psicossociais e físicas que, como explicam Papalia, Ods e Feldman (2010), são decorrentes dessa fase da vida, possibilitando um envolvimento vital na sociedade, como diria Erikson (1986).

Podemos observar que sentimentos positivos produzidos quando os idosos estão dançando e negativos quando não podem dançar os impulsionam a continuar a dançar. $E$ este engajamento, por longos períodos de tempo em determinada atividade, evidencia que a atividade é importante para seus executores. Neste caso, podemos dizer que dançar tem sido uma atividade molar (BRONFENBRENER, 2006), isto é, significativa na vida dessas pessoas, pois houve envolvimento, engajamento, persistência e prática regular em um longo período da vida.

Ao longo dos anos, foram se estabelecendo relações sociais cada vez mais sólidas; essas pessoas iniciaram observando o que os pais/amigos faziam, depois observaram outros participantes do baile, da observação vinha o querer fazer a atividade junto ou não. Como expôs um dos entrevistados ao fazer a observação de que, dependendo de como, e de quem o convidasse para dançar, não o aceitaria; ou seja, as habilidades com a dança, aliada a outros fatores levavam à manifestação de disposições, isto é, características capazes de influenciar o desenvolvimento futuro ou forças da pessoa (BRONFENBRENNER; MORRIS, 2006), que quando positivas influenciavam os processos proximais favorecendo o desenvolvimento $\mathrm{e}$ quando negativas o retardavam.

Ir ao baile oportunizou também a vivência de diferentes papéis sociais: foram dançarinos, mas foram também filhos ou enteados, padrastos, pais, violeiros, paqueradores, namorados, noivos, esposas ou maridos, amigos, motoristas, professor e alunos de dança, líderes e liderados, dentre outros.

Criaram regras, modificaram-nas, aprendiam, transformavam e transmitiam valores socioculturais, aprenderam não apenas passos de dança, mas através da possibilidade de dançar se movimentavam também entre os diferentes ambientes em que viviam, levando e trazendo as experiências adquiridas na dança para outros setores da vida, a ponto de, no final da vida afirmar que dançar é "tudo", que "não posso viver sem a dança".

As habilidades motoras se aliaram a habilidades sociais, preferências sexuais, controle de emoções e foram formando os recursos necessários para dançar e ressignificar a vida.

É interessante notar que as memórias manifestadas das experiências de dançar foram apenas positivas, embora obviamente devam ter ocorrido situações negativas também, mas eles preferiram, implicitamente, dar conotação negativa apenas à falta da dança.

Sendo assim, o impacto desta prática tem alcance muito maior do que se pode avaliar em um dado experimento, pois a prática da dança influenciou o desenvolvimento desses idosos através dos anos. Assim, pressupostos de Bronfenbrenner e Morris (2006), para explicar o desenvolvimento humano, permitem verificar que dançar ao longo da vida (atividade molar, significativa) permitiu o estabelecimento de relações com o meio ambiente, que se deram com as possibilidades de cada um em manifestar suas habilidades e dificuldades (recursos, demandas e disposições pessoais), exercer diferentes papéis sociais, formar diferentes unidades de relacionamentos interpessoais (díadas, triadas e outros), influenciando e sendo influenciado pelos diferentes locais onde se encontravam (micro e mesossistema). 
Isso ocorreu também até por ambientes onde não estavam, por exemplo, bailes em que nunca estiveram, mas que outros companheiros de dança frequentaram (exossistema) e Ihes traziam ou informação, ou novos passos de dança e pela cultura que os envolvia (macrossistema).

Assim, inseridos nesta relação processo-pessoa-contexto-tempo prevista por Bronfenbrenner $(1992,2005)$, através da prática da dança essas pessoas foram influenciando o surgimento e funcionamento de processos proximais futuros, que geraram a continuidade do processo e que poderá continuar a gerá-los, uma vez que eles continuam a praticar esta atividade.

\section{CONSIDERAÇÕES FINAIS}

Ao analisarmos os depoimentos desse grupo de idosos que ao longo da vida praticaram a dança, percebemos que essa atividade vai além do prazer momentâneo ou de benefícios pontuais, conquistados em um determinado programa de dança para idosos, tais como benefícios físicos, sociais ou psicológicos. Trata-se de um processo complexo, que influencia o desenvolvimento pessoal integral ao longo da vida.

No entanto, esta prática também pode ser vista com simplicidade e concluir-se que dançar é importante para a construção de um dia a dia que permite o prazer de se chegar à velhice, podendo transmitir a outros a vivência e alegria dessa prática.

As memórias associadas a dançar foram evocadas pelos participantes deste estudo com carinho e cuidado, eles preferiram evocar apenas boas lembranças, trazendo para 0 presente parentes e amigos que já se foram, bem como os que ainda lhes permitem sonhar com o futuro, o que nos revela que a dança possibilita a formação de interações pessoais profundas, que podem perdurar ao longo da vida e levar para a velhice sentimentos de alegria e esperança.

As memórias também trouxeram à tona disposições pessoais, lugares, sons, imagens, modos e costumes de diferentes épocas, mostrando uma viva relação entre o passado e 0 futuro, que se renova no presente, quando se dança. A habilidade de dançar pode não ser mais a mesma, assim como mudaram os locais e as pessoas, mas dançar continua a ser uma experiência fascinante que permite 0 desenvolvimento de novas possibilidades, onde se reinventam autores, lugares e culturas.

Dançando os participantes deste estudo modificaram e foram modificados pelos diferentes ambientes em que viveram. Em suma, dançar ao longo da vida modificou as possibilidades de viver e, ao chegar à etapa final da vida, dançar constitui-se em uma forma de resiliência, que alimenta a própria possibilidade de dançar e acrescenta vontade de viver. 


\section{REFERÊNCIAS}

ALLEN, Christie Kay. Irish céili dance and elderly dancers. American Journal of Dance Therapy, v. 25, n. 2, p. $111-122,2003$.

BRONFENBRENNER, Urie. Ecological Systems theory. In: VASTA, R. Six theories of child development: revised formulations and current issues. London: Jessica Kingsley Publisher, 1992, p. 133-185.

BRONFENBRENNER, Urie. A ecologia do desenvolvimento humano: experimentos naturais e planejados. Porto Alegre: Artes Médicas, 1996.

BRONFENBRENNER, Urie. The bioecological theory of human development. In: BRONFENBRENNER, Urie. (Org.). Making human beings human: Bioecological perspectives on human development. Melbourne: Sage, 2005. p. 106-173.

BRONFENBRENNER, Urie; MORRIS, Pamela A. The Bioecological Model of Human Development. In: DAMON, William; LERNER, Richard. M. Handbook of Child Psychology. $6^{\text {th }}$ ed. New Jersey: John Wiley, 2006. v.1, p.793-825.

BURKE, Peter. A escrita da História. São Paulo, EDUNESP, 1992.

CARTA, Mauro Giovani et al. Improving physical quality of life with group physical activity in the adjunctive treatment of major depressive disorder Clinical Practice \& Epidemiology in Mental Health, v.4, n.1, p.1-6, 2008.

CASSIANO, Janine Gomes et al. Dança sênior: um recurso na intervenção terapêuticoocupacional junto a idosos hígidos. Revista Brasileira de Ciências do Envelhecimento Humano, v. 6, n. 2, p. 204-212, 2009.

CONNOR, Margaret. Recreational folk dance: A multicultural exercise component in healthy ageing. Australian Occupational Therapy Journal, v. 47, n.1, p. 69-76, 2000.

COOPER, Lesley; THOMAS, Helen. Growing old gracefully: social dance in the third age. Ageing \& Society, v. 22, n.1, p. $689-708,2002$.

COUDERT, Jean; VAN PRAAGH, Emmanuel. Endurance Exercise training in the elderly: effects on cardiovascular function. Current Opinion in Clinical Nutrition \& Metabolic Care, v.3, n.6, 479-483, 2000.

ENGELS, Hermann Joseph et al. Effects of low impact, moderate-intensity exercise training with and without wrist weights on functional capacities and mood states in older adults. Gerontology, v.44, n.4, p.239-244, 1998.

ERIKSON, Erik et al. Vital involvement in old age. New York: W.W. Norton, 1986.

EYIGOR, Siber et al. A randomized controlled trial of Turkish folklore dance on the physical performance, balance, depression and quality of life in older women. Archives of Gerontology and Geriatrics, v. 48 n.1, p. 84-88, 2009.

FLEURY, Tania Maria Assis; GONTIJO, Daniela Tavares. As danças circulares e as possíveis contribuições da terapia ocupacional para as idosas. Estudos interdisciplinares sobre o envelhecimento, v. 9, n.1, p. 75-90, 2006. 
HUI, Elsie; CHUI, Bo. Tsan-keung; WOO, Jean. Effects of dance on physical and psychological well-being in older persons. Archives of Gerontology and Geriatrics, v.49, p.45-50, 2009.

INSTITUTO BRASILEIRO DE GEOGRAFIA E ESTATÍSTICA (IBGE). Práticas de esporte e atividade física: 2015 / IBGE, Coordenação de Trabalho e Rendimento. Rio de Janeiro, 2017.

JEON, Mi Yang; CHOE, Myoung Ae; CHAE, Young Ran. Effect of Korean traditional dance movement training on balance, gait and strength in homebound elderly women. Journal of Korean Academic Nursing, v 30, n. 3, p. $647-658,2000$.

JEON, Mi Yang et al. The effects of a Korean traditional dance movement program in elderly women. Taehan Kanho Hakhoe Chi, v. 35, n. 7, p. 1268-1276, 2005.

KNUTH, Alan Goularte et al. Prática de atividade física e sedentarismo em brasileiros: resultados da Pesquisa Nacional por Amostra de Domicílios (PNAD) - 2008. Ciência \& Saúde Coletiva, v. 16, n.9, p. 3697-3705, 2011.

LEAL, Indara Jubin; HAAS, Aline Nogueira. O significado da dança na terceira idade. Revista Brasileira de Ciências do Envelhecimento Humano, v.3, n.1, p.64 - 71, 2006.

LIMA, Maristela Moura Silva; VIEIRA, Alba Pedreira. Ballroom dance as therapy for elderly in Brazil. American journal of dance therapy, v.29, n.2, p.129 - 142, 2007.

LUDKE, Menga; ANDRE, Marli Elisa D.A. Pesquisa em educação: abordagens qualitativas. São Paulo: EPU, 1986.

MAVROVOUNIOTIS, Fotios; ARGIRIADOU, Eirini A.; PAPAIOANNOU, Cristina. Greek traditional dances and quality of old people's life. Journal of body work \& movement therapies, v.14, n.1, p. $209-218,2008$.

MCKINLEY, Patricia Anne et al. Effect of a community-based argentine tango dance program on functional balance and confidence in older adults. Journal of Aging and Physical Activity, v.16, n.1, p. 435-453, 2008.

OLIVEIRA, Rafael Gonçalvez de; TOLOCKA, Rute Estanislava. Inclusão social e pessoas que participam de bailes em uma instituição de longa permanência para idosos. Revista de Educação Física/UEM, v. 20, n.1, p 85- 89, 2009.

PAPALIA, Daiane. E; OLDS, Saly Wendkos; FELDMAN, Ruth Duskin. Desenvolvimento humano. Porto Alegre: Artmed, 2010.

PEREIRA, Rafael, SCHETTINO, Ludimila, MACHADO, Marco. Development of muscular explosive force in older women: influence of a dance-based exercise routine Medicina Esportiva, v. 14, n.4, p. 209-213, 2010.

SHIGEMATSU, Ryosuke et al. Dance- based aerobic exercise may improve indices of falling risk in older women. Age and ageing, v. 31, n. 4, p. 261-266, 2002.

SILVA, Aline Uber da; MAZO, Giovana Zarpelon. Dança para idosos: uma alternativa para o exercício físico. Cinergis, v.8, n.1, p.25-32, jan./jun. 2007.

SILVA, Erineusa Maria da et al. A (re)descoberta de si: implicações e aprendizagens produzidas a partir do projeto "Cuidadores que dançam". Movimento, v. 22, n.3, p. 889-900, jul./set. 2016. 
SOFIANIDIS, Giorgos et al. Effect of a 10-Week Traditional Dance Program on Static and Dynamic Balance Control in Elderly Adults. Journal of Aging and Physical Activity, v. 17, n.1, p. 167-180, 2009.

THOMPSON, Paul. A voz do passado: História oral. Rio de Janeiro: Paz e Terra, 1992.

VALLE, Rodrigo Gomes de Souza et al. Efeitos do treinamento resistido na força máxima, na flexibilidade e na autonomia funcional de mulheres idosas. Revista Brasileira de

Cineantropometria e Desempenho Humano, v.8, n.4, p. 52-58, 2006.

VERGHESE, Joe. Cognitive and mobility profile of folder social dancers. Journal of American Geriatric Society, v. 54, n. 8, p. $1241-1244,2006$.

WALLMANN, Harvey W. et al. The Effect of a Senior Jazz Dance Class on Static Balance in Healthy Women Over 50 Years of Age: A Pilot Study. Biological Research for Nursing, v.10, n.3, p. 257-266, 2009.

WU, Wen-La et al. The effect of Chinese Yuanji-Dance on dynamic balance and the associated attentional demands in elderly adults. Journal of Sports Science and Medicine, v. 9, n. 1, p.119-126, 2010.

ZHANG, Jian-Guo et al. Postural stability and physical performance in social dancers. Gait \& Posture, v. 27, n.1, p.697-701, 2008. 


\section{Apoio:}

Conselho Nacional de Pesquisa (CNPq). 